\title{
Use of Methotrexate for the Treatment of Ocular Inflammation and Uveitis
}

Se Joon Woo ${ }^{1 *}$, and Eun Ha Kang ${ }^{2}$

${ }^{1}$ Department of Ophthalmology, Seoul National University College of Medicine, Seoul National University Bundang Hospital, Seongnam, Korea ${ }^{2}$ Division of Rheumatology, Department of Internal Medicine, Seoul National University Bundang Hospital, Seongnam, Korea

\begin{abstract}
Methotrexate is an immunosuppressive agent used for the management of ocular inflammatory diseases and rheumatic diseases. Despite its use for ocular inflammation, including uveitis, since 1965, the exact efficacy of methotrexate has not been confirmed by a randomized clinical trial thus far. Our review of previous data of treatment outcomes suggested that methotrexate is moderately effective in suppressing ocular inflammation and decreasing corticosteroid use. In addition, methotrexate is relatively safe and well tolerated by most patients and is the most widely used immunosuppressive drug for the treatment of uveitis in children. In addition to systemic administration of the drug, intraocular administration of methotrexate can be a promising treatment option for uveitis.
\end{abstract}

Keywords: Methotrexate; Ocular inflammation; Uveitis; Immunosuppressive; Immunomodulatory; Rheumatic disease; Rheumatoid arthritis

Abbreviations: MTX: Methotrexate; DHFR: Dihydrofolate Reductase; AICAR: 5-aminoimidazole-4-Carboxamide Ribonucleotide; RA: Rheumatoid Arthritis; DMARD: Disease-Modifying AntiRheumatic Drug; ANCA: Anti-Neutrophil Cytoplasmic Antibody; CBC: Complete Blood Cell Count; LFT: Liver Function Test; CSSR: Corticosteroid-Sparing Rate; ROS: Reactive Oxygen Species

\section{Introduction}

Non-infectious ocular inflammatory diseases (e.g., intraocular inflammation or uveitis) are triggered by the interaction between genetic and environmental factors and subsequent activation of the immune system and the main therapeutic regimen for these diseases includes anti-inflammatory drugs. Thus, the rationale for the use of methotrexate (MTX) in ocular inflammation is similar to that in rheumatic diseases. Although MTX has been used for treating ocular inflammatory diseases for many years and its effectiveness has been described in many studies, the precise efficacy of MTX has not been proven using a well-designed controlled trial. Thus, we reviewed the current use of MTX and the safety issues associated with its use in the treatment of ocular inflammation. The aim of this review was to summarize the current knowledge about the use of MTX for treating ocular inflammation for physicians and specialists of uveitis and rheumatology.

\section{Mechanism of Action of MTX and its Application in Rheumatic Diseases}

MTX is categorized as an antimetabolite and is a folate antagonist that competitively inhibits dihydrofolate reductase (DHFR). DHFR catalyzes the transfer of a hydride to dihydrofolate to produce tetrahydrofolate (Figure 1), which is essential for the synthesis of the nucleic acid building blocks, purines and thymidines. MTX inhibits cell growth and proliferation by depleting the pool of reduced folates or tetrahydrofolates. Therefore, MTX is cytotoxic during the S-phase of the cell cycle and shows a greater toxic effect on the rapidly proliferating cells. The anticancer effect of MTX can be attributed to this anti-proliferative action of the drug. Further, different mechanisms are thought to be involved in the anti-inflammatory effect of MTX in arthritis or other rheumatic diseases. In rheumatic diseases, MTX is administered intermittently (weekly) in doses two or three log orders lower than those required for anticancer therapy (5-25 mg/week vs. $5000 \mathrm{mg} /$ week). The toxicity of low-dose MTX decreases upon folic acid supplementation without the loss of efficacy [1], which indicates that MTX exerts its anti-inflammatory action via mechanisms other than its anti-proliferative effect. Low-dose MTX may act via a number of intracellular pathways (Figure 1). MTX is converted to polyglutamated forms in the cells by polyglutamate synthetase. These polyglutamates not only help cellular retention of the drug but also inhibit a number of folate-dependent enzymes, including DHFR and5-aminoimidazole-4carboxamide ribonucleotide (AICAR) transformylase [2]. Inhibition of AICAR transformylase leads to intracellular accumulation of AICAR, which in turn leads to inhibition of AMP deaminase and accumulation of AMP [2]. Extracellular release of AMP results in its conversion to adenosine by the action of CD73 [3]. Findings from the studies in which adenosine receptors were blocked or deleted $[4,5]$ support the role of the adenosine released as an endogenous anti-inflammatory mediator. Additional pharmacological mechanisms possibly involved in the anti-inflammatory action of MTX include the production of reactive oxygen species(ROS) from $T$ cells and monocytes [6], rendering $T$ cells susceptible to apoptosis via ROS-dependent c-Jun $\mathrm{N}$-terminal kinase (JNK) activation [7], or suppressing the expression of cytokines or adhesion molecules $[8,9]$. Some of these mechanisms may be mediated by the release of adenosine. However, the mechanism of action of MTX has not been completely elucidated to date.

The folic acid analogue aminopterin was used for the first time for the treatment of rheumatoid arthritis (RA), psoriasis, and psoriatic arthritis in 1951 [10]; since then, the related compound MTX has become the disease-modifying anti-rheumatic drug (DMARD) of

*Corresponding author: Se Joon Woo, M.D., Ph.D., Department of Ophthalmology, Seoul National University Bundang Hospital, \#300, Gumi-dong, Bundang-gu, Seongnam, Gyeonggi-do 463-707, South Korea, Tel: +82-31-7877377; Fax: +82-31-787-4057; E-mail: sejoon1@snu.ac.kr

Received September 16, 2013; Accepted November 23, 2013; Published December 02, 2013

Citation: Woo SJ, Kang EH (2013) Use of Methotrexate for the Treatment of Ocular Inflammation and Uveitis. J Pharmacovigilance 1: 117. doi:10.4172/23296887.1000117

Copyright: (ㅇ 2013 Woo SJ, et al., This is an open-access article distributed under the terms of the Creative Commons Attribution License, which permits unrestricted use, distribution, and reproduction in any medium, provided the original author and source are credited. 


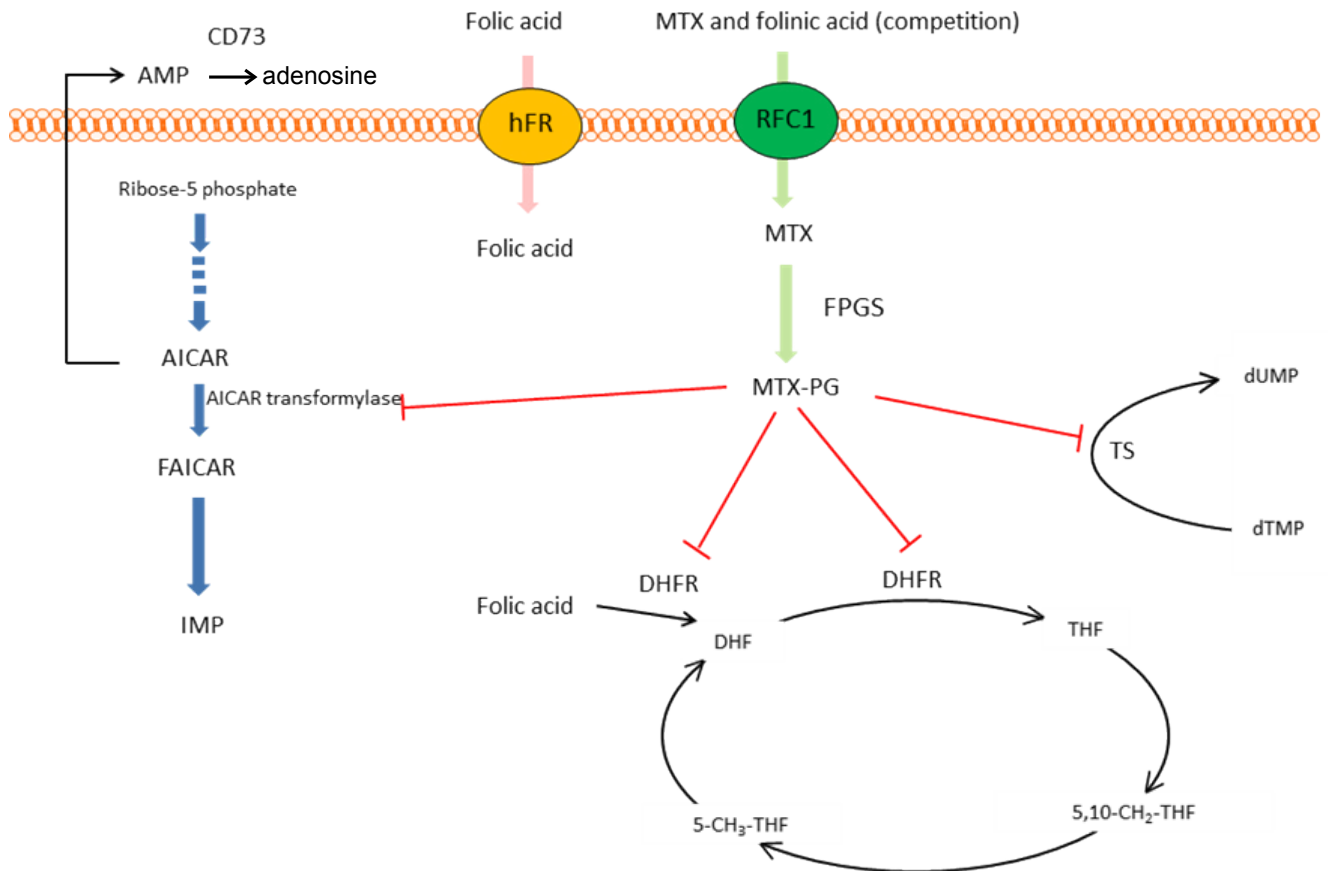

Figure 1: Mechanisms of action of methotrexate (MTX). Two major pathways are depicted: (1) inhibition of dihydrofolate reductase and subsequent depletion of tetrahydrofolate (THF) required for purine and pyrimidine synthesis and (2) inhibition of aminoimidazole carboxamide ribonucleotide (AICAR) transformylase and subsequent release of adenosine. The former action is thought to mediate the antiproliferative effect of MTX while the latter is thought to mediate its antiinflammatory effect.

Where,

AICAR=aminoimidazole carboxamide ribonucleotide

AMP=adenosine monophosphate

FAICAR=formyl AICAR

hFR=human folate receptor

$\mathrm{DHFR}=$ dihydrofolate reductase

dTMP=deoxythymidine monophosphate

dUMP=deoxyuridine monophosphate

FPGS=folypolyglutamate synthetase

IMP=inosine monophosphate

MTX-PG=methotrexate polyglutamate

$\mathrm{RFC} 1=$ reduced folate carrier 1

THF=tetrahydrofolate

TS=thymidylate synthase

Note: This figure does not depict the entire range of the intracellular effects of MTX.

choice for RA because of its superior efficacy-to-toxicity ratio [11]. MTX significantly improves the clinical symptoms and signs of arthritis and slows the radiographic progression in RA [12]. Disease-modifying benefits of MTX similar to those in RA have been observed in various rheumatic conditions such as lupus, myositis, psoriasis, vasculitis, and ocular inflammation (Table 1).

\section{MTX for Ocular Inflammatory Diseases}

MTX was used for ocular inflammatory diseases for the first time in 1965 [13]. Although corticosteroid administration is the initial treatment for the management of non-infectious ocular inflammatory diseases, immunosuppressive (or immunomodulatory) agents, including MTX, are administered in addition to corticosteroids in patients refractory to corticosteroid treatment or to prevent steroid-induced side effects $[14,15]$. The current use of MTX for ocular inflammatory diseases is summarized in Table 2 .

Similar to its administration in rheumatic diseases, MTX is administered intermittently at low doses (7.5-25 mg/kg per week orally) with folic acid supplementation in ocular inflammation [14].
Parenteral administration via subcutaneous or intramuscular injections may increase the bioavailability and improve tolerance in patients with gastrointestinal disorders. MTX requires 6 to 8 weeks to be completely effective [16]; therefore, MTX is usually initially combined with a high dose of corticosteroid. After an improvement in ocular inflammation, the dose of the oral corticosteroid is tapered or its administration is discontinued. Administration of MTX is usually continued for 6 to 24 months at an effective dose, and then the MTX dose is tapered over 3 to 12 months, but the exact tapering schedule has not been determined thus far. The precise dosage regimen should be individualized on the basis of the patient's desires, compliance, medical and social conditions, and complications.

MTX therapy is indicated in almost all types of ocular inflammation, including anterior, intermediate, posterior, and panuveitis, retinal vasculitis, scleritis, childhood chronic uveitis, and mucus membrane pemphigoid [17-19]. Other specific indications include Behçet disease [20], birdshot chorioretinopathy [21], multifocal choroiditis with panuveitis [22,23], sarcoidosis [24], Vogt-Koyanagi-Harada disease [25], and sympathetic ophthalmia [26]. In addition, complications 
Citation: Woo SJ, Kang EH (2013) Use of Methotrexate for the Treatment of Ocular Inflammation and Uveitis. J Pharmacovigilance 1: 117. doi:10.4172/23296887.1000117

Page 3 of 6

\begin{tabular}{|c|c|c|}
\hline Rheumatic diseases & Indications for MTX & Benefits \\
\hline Rheumatoid arthritis [13] & Initial treatment of rheumatoid arthritis for all patients unless contraindicated & $\begin{array}{c}\text { Improves signs of inflammation and symptoms and } \\
\text { retards structural damage }\end{array}$ \\
\hline Psoriasis [22] & Moderate to severe psoriasis, when the disease is not responding to topical & Reduces area and severity of the affected skin \\
\hline Lupus & Particularly whents or phototherapy & Fire involved \\
\hline Myositis [23] & Steroid refractory myositis & Reduces the relapse rate and cumulative steroid dose \\
\hline Vasculitis [24,25] & $\begin{array}{c}\text { Non-life threatening ANCA-positive vasculitis instead of cyclophosphamide } \\
\text { or large vessel vasculitis adjunctively with corticosteroids }\end{array}$ & Reducr corticosteroids \\
\hline
\end{tabular}

MTX: Methotrexate; ANCA: Anti-Neutrophil Cytoplasmic Antibody

Table 1: Rheumatic diseases in which low-dose methotrexate is commonly used.

\begin{tabular}{|c|c|c|}
\hline Dosage & $\begin{array}{c}\text { 7.5-25 mg/week PO, SC, or IM + folic acid } 1 \\
\mathrm{mg} / \mathrm{d}\end{array}$ & $\begin{array}{c}\text { Dose escalation regimen (Initial, } 7.5-12.5 \mathrm{mg} / \text { week; maximum, } 25 \mathrm{mg} / \\
\text { week) or } \\
\text { Initial high-dose regimen; } \\
400 \mu \mathrm{g} \text { in } 0.1 \mathrm{~mL} \text { for intravitreal injection }\end{array}$ \\
\hline Full efficacy & $6-8$ weeks & \\
\hline Follow-up monitoring & CBC, LFT per 6-8 weeks & \\
\hline \multirow[t]{6}{*}{ Indications (responsiveness*) $[17,18]$} & Anterior uveitis & (Responsiveness $^{*}=55.6 \% ;$ CSSR $\left.=46.1 \%\right)$ \\
\hline & Intermediate uveitis & (Responsiveness = 47.4\%; CSSR = 41.3\%) \\
\hline & Posterior or panuveitis & (Responsiveness $=38.6 \% ;$ CSSR $=20.7 \%)$ \\
\hline & Scleritis & (Responsiveness $=56.4 \% ;$ CSSR $=37.3 \%)$ \\
\hline & Ocular membrane pemphigoid & (Responsiveness=39.5\%; CSSR = 36.5\%) \\
\hline & Childhood chronic uveitis & $($ Responsiveness $=73 \%)$ \\
\hline \multirow[t]{11}{*}{ Adverse reactions (incidence) $[17,30]$} & Gastrointestinal distress & $(2.9-10.0 \%)$ \\
\hline & Bone marrow suppression & $(2.6-3.1 \%)$ \\
\hline & Increased levels of liver enzymes & $(2.3-6.9 \%)$ \\
\hline & Malaise & $(2.1-13.1 \%)$ \\
\hline & Anorexia/nausea & $(6.9 \%)$ \\
\hline & Allergy & $(1.6 \%)$ \\
\hline & Mouth ulcers & $(1.3 \%)$ \\
\hline & Infections & $(0.8 \%)$ \\
\hline & Respiratory complaints & $(0.5 \%)$ \\
\hline & Hair loss & $(0.5 \%)$ \\
\hline & Liver cirrhosis & $(0.3 \%)$ \\
\hline
\end{tabular}

MTX: Methotrexate; CBC: Complete Blood Cell Count; LFT: Liver Function Test; CSSR: Corticosteroid-sparing rate ( $\leq 10 \mathrm{mg} / \mathrm{d})$

${ }^{*}$ Responsiveness was defined as the complete suppression of inflammation sustained $\geq 28$ days.

Table 2: Use of methotrexate in ocular inflammatory diseases and its side effects.

associated with chronic uveitis such as macular edema, choroidal neovascularization, and optic disc edema can be improved with MTX $[23,27,28]$.

However, no randomized clinical trial has been performed thus far to evaluate the efficacy of MTX in ocular inflammatory diseases; thus, the efficacy and safety of MTX must be assessed on the basis of uncontrolled case series [29] or meta-analysis [18]. Two large retrospective cohort studies are worth mentioning here. Samson et al. [30] reviewed 160 patients who took MTX either as a primary or as a steroid-sparing agent for chronic non-infectious uveitis in one center. Their study showed that MTX treatment controlled inflammation(less than $1+$ inflammatory cells within a minimum of 6 consecutive months) in $76 \%$ of patients and achieved a steroid-sparing effect in $56 \%$ of patients. Maintenance or improvement of vision was achieved in $90 \%$ of patients. Gangaputra et al. [17] included 384 patients with non-infectious ocular inflammation who took MTX from 4 centers and showed a $66 \%$ success rate of controlling inflammation (complete suppression of inflammation sustained $\geq 28$ days) and a $58.4 \%$ success rate for corticosteroid-sparing effect $(\leq 10 \mathrm{mg} / \mathrm{d})$. Data from previous studies indicate that combination of MTX with corticosteroids is moderately effective for the management of intraocular inflammatory diseases.
In pediatric patients, corticosteroid use is associated with a potential risk of irreversible growth suppression despite the presence of human growth hormones [31]. MTX has been used in many children with RA, which proves the relative safety of MTX use in children [32]. Thus, MTX is the most commonly used immunosuppressive agent in children. Because of the differences in metabolism, the oral dose of MTX in children (10 to $25 \mathrm{mg} / \mathrm{m}^{2}$ or 7.5 to $15 \mathrm{mg}$ per week) is higher than that in adults. A recent meta-analysis [18] of nine retrospective case series $(\mathrm{N}=135)$ showed the effectiveness of MTX for the treatment of childhood autoimmune chronic uveitis; the authors showed that the responsiveness was 0.73 (95\% CI, 0.66-0.81), which suggested a favorable effect in the improvement of intraocular inflammation. MTX appears to be effective in childhood uveitis associated with juvenile idiopathic arthritis $[33,34]$, but the relapse rate was reported to be high (69\%) [35].

In addition, MTX can be administered intravitreally at a dose of $400 \mu \mathrm{g}$ in $0.1 \mathrm{~mL}$. Recently, several studies have shown that intravitreal injection of MTX is effective for the treatment of uveitis with no serious ocular side effects [20,23,36-38]. Intravitreal administration can be advantageous because it can avoid the potential side effects of systemic corticosteroids and immunosuppressive agents, especially in patients with unilateral uveitis. Thus, intravitreal administration can be a promising route of administration for patients who are vulnerable to 


\begin{tabular}{|c|c|}
\hline Any side effects & $72.9 \%$ \\
\hline Termination rates because of toxicity & $10.5 \%$ \\
\hline Gastrointestinal symptoms (stomatitis, nausea, or stomach upset) & $30.8 \%$ \\
\hline Increased levels of liver enzymes & $20.2 \%$ \\
\hline Skin/hair & $8.9 \%$ \\
\hline Myelosuppression & $5.2 \%$ \\
\hline Pneumonitis & $0.43 \%$ \\
\hline
\end{tabular}

†Pooled analysis of 3463 rheumatoid arthritis patients from 21 prospective cohorts who had been treated with methotrexate (MTX) for a mean duration of 36.5 months.

Table 3: Adverse effects attributed to low-dose methotrexate treatment for rheumatoid arthritis [40].

systemic immunosuppressive therapy (e.g., pregnant women, children, or patients with liver dysfunction). However, further studies are required to provide sufficient evidence for using intravitreal MTX for ocular inflammatory diseases.

\section{Adverse Effects of MTX use for ocular inflammation and rheumatic diseases}

Despite its effectiveness as a disease-modifying agent, the probability of discontinuation of MTX is 34\% in 2 years in RA patients [39]. The major factor for discontinuation of MTX is the development of adverse events [14] probably owing to folate antagonism or folate deficiency. Although the rate of adverse events was as high as $73 \%$ in RA patients during 3 years of treatment in a pooled analysis by Salliot and van der Heijde [40], the frequency of serious adverse events was not high, and long-term use of MTX did not seem to increase the risk of infection. The toxicities associated with MTX are enlisted in Table 3.

The toxicity of MTX is significantly reduced with folate supplementation in RA patients [41,42]. Although folinic acids, which are reduced forms of folic acids, also reduce MTX-mediated toxicity, they reverse the therapeutic efficacy of MTX against RA owing to competitive inhibition of folinic acids with MTX during cellular transport [43]. The discrepancy between folates and folinic acids against MTX-mediated efficacy is explained by their transport system. Transport of folates into the mammalian cells occurs via receptor-mediated or carriermediated mechanisms. The human folate receptor shows much higher affinity to folate than to MTX, and its expression is limited in specific tissues (kidney, lung, choroid plexus, and placenta) [44]. Because the capacity of the receptor is low, receptor-mediated transport operates when folates are present at low concentrations. Therefore, folate supplementation may have a little influence on the action of MTX. On the other hand, reduced folate carriers are ubiquitously expressed and show lower affinity and higher capacity than folate receptors [44]. This carrier-mediated transport system represents the major transport system for folates, folate derivatives (including folinic acids), and MTX. It preferentially binds to folinic acids than to folates or MTX with the lowest affinity to MTX. Therefore, folinic acid supplementation can reduce the efficacy of MTX by competitive inhibition of intracellular transport of MTX. Thus, there seems no reason on current evidence to recommend the use of folinic acids in preference to folic acids for routine administration. However, because folinic acids can circumvent DHFR (a molecular target of MTX) in biosynthetic pathways, folinic acids retain an important role in the treatment of MTX overdose or acute hematological toxicity.

Unlike many adverse events related to folate metabolism, pulmonary toxicity or MTX-induced pneumonitis is an unpredictable but potentially life-threatening complication that occurs during MTX treatment in a dose-independent manner [45]. The prevalence of pulmonary toxicity or MTX-induced pneumonitis ranges from 0.3 to
$0.7 \%$ [45], and the histological findings associated with MTX-induced pneumonitis were not different from those associated with lung toxicities caused by other drugs [46,47]. The risk factors for MTX-induced pneumonitis include old age, diabetes, rheumatoid pleuropulmonary involvement, previous use of DMARDs, and hypoalbuminemia [48]. The mechanism of this adverse event is unknown but is presumed to involve a hypersensitivity reaction in the case of some patients [46]. When a patient is suspected to have MTX-induced pneumonitis, immediate cessation of MTX and administration of corticosteroids is recommended. A patient who recovers from MTX-induced lung injury tends to relapse with retreatment [47].

MTX has been reported to cause fetal death and/or congenital anomalies. Therefore, MTX is not recommended for women of childbearing potential unless the benefits are expected to outdo the risks.

Most studies on the safety of MTX for ocular inflammatory diseases showed that the use of low-dose MTX has little risk of serious side effects during treatment (Table 2). In a retrospective study by Gangaputra et al. [17], MTX was discontinued because of the following side effects in $16 \%$ of 384 patients: gastrointestinal distress (2.9\%), bone marrow suppression $(2.6 \%)$, increased levels of liver enzymes $(2.3 \%)$, malaise $(2.1 \%)$, allergy (1.6\%), mouth ulcers $(1.3 \%)$, infections $(0.8 \%)$, respiratory complaints $(0.5 \%)$, hair loss $(0.5 \%)$, liver cirrhosis $(0.3 \%)$, and others (1.8\%). Each event rate for these side effects per personyear was equal to or less than 0.02 , which indicates a very low risk of complications. Similar results were reported by Samson et al. [30], that discontinuation of MTX owing to side effects was necessary in $18 \%$ of 160 patients without long-term morbidity or mortality. Potentially serious adverse effects occurred in only $8.1 \%$ of patients. If non-healththreatening side effects were included, the incidence of total side effects was $42.5 \%$; these side effects included fatigue (13.1\%), anorexia/nausea (6.9\%), increased levels of liver enzymes (6.9\%), diarrhea (5.6\%), stomatitis $(4.4 \%)$, and leukopenia $(3.1 \%)$. The lower incidence of side effects in patients with ocular inflammatory diseases (overall, $42.5 \%$ and $16-18 \%$ requiring MTX discontinuation) than in those with rheumatic diseases (overall, $73 \%$ and $34 \%$ requiring MTX discontinuation) may be because of the relatively low dosage and short period of MTX use for ocular inflammatory diseases.

\section{Conclusion}

Although the efficacy of MTX has not been proven using a randomized clinical trial, the cumulative clinical experience since 1960s suggests that MTX is an effective drug for the management of intraocular inflammation. Systemic administration of low doses of MTX is moderately effective in suppressing inflammation and in decreasing the dose of corticosteroids in patients with nearly all types of ocular inflammatory diseases. Moreover, MTX is well tolerated by patients (including pediatric patients), and the risk of side effects associated with MTX is very low. Intravitreal administration can be a promising therapeutic option for the management of intraocular inflammatory diseases in the future.

\section{Highlights}

1. The two mechanisms of action by which MTX exerts its effects in ocular inflammation and rheumatic diseases are as follows: an anti-proliferative effect on inflammatory cells and extracellular release of adenosine as an endogenous antiinflammatory mediator

2. Systemic low-dose methotrexate is moderately effective in 
Citation: Woo SJ, Kang EH (2013) Use of Methotrexate for the Treatment of Ocular Inflammation and Uveitis. JPharmacovigilance 1: 117. doi:10.4172/23296887.1000117

Page 5 of 6

suppressing inflammation and in decreasing corticosteroid use in ocular inflammation and uveitis similar to that in other rheumatic diseases.

3. Methotrexate is relatively safe and well tolerated by most patients with uveitis and is the most widely used immunosuppressive drug for children.

4. Intravitreal administration of MTX can be a promising therapeutic option for the management of intraocular inflammatory diseases in the future.

\section{Acknowledgment}

This study was partly supported by the National Research Foundation (NRF) of Korea grant (Grant No. 2012R1A2A2A02012821) funded by the Ministry of Education, Science, and Technology.

\section{References}

1. Visser K, Katchamart W, Loza E, Martinez-Lopez JA, Salliot C, et al. (2009) Multinational evidence-based recommendations for the use of methotrexate in rheumatic disorders with a focus on rheumatoid arthritis: integrating systematic literature research and expert opinion of a broad international panel of rheumatologists in the 3E Initiative. Ann Rheum Dis 68: 1086-1093.

2. Cutolo M, Sulli A, Pizzorni C, Seriolo B, Straub RH (2001) Anti-inflammatory mechanisms of methotrexate in rheumatoid arthritis. Ann Rheum Dis 60: 729

3. Montesinos MC, Yap JS, Desai A, Posadas I, McCrary CT, et al. (2000) Reversal of the antiinflammatory effects of methotrexate by the nonselective adenosine receptor antagonists theophylline and caffeine: evidence that the antiinflammatory effects of methotrexate are mediated via multiple adenosine receptors in rat adjuvant arthritis. Arthritis Rheum 43: 656-663.

4. Montesinos MC, Takedachi M, Thompson LF, Wilder TF, Fernandez P, et al. (2007) The antiinflammatory mechanism of methotrexate depends on extracellular conversion of adenine nucleotides to adenosine by ecto-5'nucleotidase: findings in a study of ecto-5'-nucleotidase gene-deficient mice. Arthritis Rheum 56: 1440-1445

5. Montesinos MC, Desai A, Cronstein BN (2006) Suppression of inflammation by low-dose methotrexate is mediated by adenosine A2A receptor but not A3 receptor activation in thioglycollate-induced peritonitis. Arthritis Res Ther 8 R53

6. Phillips DC, Woollard KJ, Griffiths HR (2003) The anti-inflammatory actions of methotrexate are critically dependent upon the production of reactive oxygen species. Br J Pharmacol 138: 501-511.

7. Spurlock CF 3rd, Aune ZT, Tossberg JT, Collins PL, Aune JP, et al. (2011) Increased sensitivity to apoptosis induced by methotrexate is mediated by JNK Arthritis Rheum 63: 2606-2616.

8. Rudwaleit M, Yin Z, Siegert S, Grolms M, Radbruch A, et al. (2000) Response to methotrexate in early rheumatoid arthritis is associated with a decrease of $T$ cell derived tumour necrosis factor alpha, increase of interleukin 10, and predicted by the initial concentration of interleukin 4. Ann Rheum Dis 59: 311-314.

9. Dolhain RJ, Tak PP, Dijkmans BA, De Kuiper P, Breedveld FC, et al. (1998) Methotrexate reduces inflammatory cell numbers, expression of monokines and of adhesion molecules in synovial tissue of patients with rheumatoid arthritis. Br J Rheumatol 37: 502-508.

10. GUBNER R, AUGUST S, GINSBERG V (1951) Therapeutic suppression of tissue reactivity. II. Effect of aminopterin in rheumatoid arthritis and psoriasis. Am J Med Sci 221: 176-182.

11. Felson DT, Anderson JJ, Meenan RF (1992) Use of short-term efficacy/toxicity tradeoffs to select second-line drugs in rheumatoid arthritis. A metaanalysis of published clinical trials. Arthritis Rheum 35: 1117-1125.

12. Gaujoux-Viala C, Smolen JS, Landewé R, Dougados M, Kvien TK, et al. (2010) Current evidence for the management of rheumatoid arthritis with synthetic disease-modifying antirheumatic drugs: a systematic literature review informing the EULAR recommendations for the management of rheumatoid arthritis. Ann Rheum Dis 69: 1004-1009.

13. Wong VG (1966) Methotrexate treatment of uveal disease. Am J Med Sci 251 239-241.
14. Jabs DA, Rosenbaum JT, Foster CS, Holland GN, Jaffe GJ, et al. (2000) Guidelines for the use of immunosuppressive drugs in patients with ocular inflammatory disorders: recommendations of an expert panel. Am J Ophthalmo 130: $492-513$.

15. Okada AA (2005) Immunomodulatory therapy for ocular inflammatory disease: a basic manual and review of the literature. Ocul Immunol Inflamm 13: 335-351.

16. Shah SS, Lowder CY, Schmitt MA, Wilke WS, Kosmorsky GS, et al. (1992) Lowdose methotrexate therapy for ocular inflammatory disease. Ophthalmology 99 1419-1423.

17. Gangaputra S, Newcomb CW, Liesegang TL, Kacmaz RO, Jabs DA, et al. (2009) Methotrexate for ocular inflammatory diseases. Ophthalmology 116: 2188-2198.

18. Simonini G, Paudyal P, Jones GT, Cimaz R, Macfarlane GJ (2013) Current evidence of methotrexate efficacy in childhood chronic uveitis: a systematic review and meta-analysis approach. Rheumatology (Oxford) 52: 825-831.

19. Kaplan-Messas A, Barkana Y, Avni I, Neumann R (2003) Methotrexate as a first-line corticosteroid-sparing therapy in a cohort of uveitis and scleritis. Ocul Immunol Inflamm 11: 131-139.

20. Bae JH, Lee SC (2012) Effect of intravitreal methotrexate and aqueous humo cytokine levels in refractory retinal vasculitis in Behcet disease. Retina 32 1395-1402.

21. Rothova A, Ossewaarde-van Norel A, Los LI, Berendschot TT (2011) Efficacy of low-dose methotrexate treatment in birdshot chorioretinopathy. Retina 31 1150-1155.

22. Michel SS, Ekong A, Baltatzis S, Foster CS (2002) Multifocal choroiditis and panuveitis: immunomodulatory therapy. Ophthalmology 109: 378-383.

23. Mateo-Montoya A, Baglivo E, de Smet MD (2013) Intravitreal methotrexate for the treatment of choroidal neovascularization in multifocal choroiditis. Eye (Lond) 27: 277-278.

24. Dev S, McCallum RM, Jaffe GJ (1999) Methotrexate treatment for sarcoidassociated panuveitis. Ophthalmology 106: 111-118.

25. Kondo Y, Fukuda K, Suzuki K, Nishida T (2012) Chronic noninfectious uveitis associated with Vogt-Koyanagi-Harada disease treated with low-dose weekly systemic methotrexate. Jpn J Ophthalmol 56: 104-106.

26. Wong VG, Hersh EM, McMaster PR (1966) Treatment of a presumed case of sympathetic ophthalmia with methotrexate. Arch Ophthalmol 76: 66-76.

27. Woo SJ, Kim MJ, Park KH, Lee YJ, Hwang JM (2012) Resolution of recalcitran uveitic optic disc edema following administration of methotrexate: two case reports. Korean J Ophthalmol 26: 61-64.

28. Mackensen F, Jakob E, Springer C, Dobner BC, Wiehler U, et al. (2013) Interferon versus methotrexate in intermediate uveitis with macular edema: results of a randomized controlled clinical trial. Am J Ophthalmol 156: 478-486.

29. Ali A, Rosenbaum JT (2010) Use of methotrexate in patients with uveitis. Clin Exp Rheumatol 28: S145-150.

30. Samson CM, Waheed N, Baltatzis S, Foster CS (2001) Methotrexate therapy for chronic noninfectious uveitis: analysis of a case series of 160 patients. Ophthalmology 108: 1134-1139.

31. Polito C, La Manna A, Papale MR, Villani G (1999) Delayed pubertal growth spurt and normal adult height attainment in boys receiving long-term alternateday prednisone therapy. Clin Pediatr (Phila) 38: 279-285.

32. Wallace CA (1998) The use of methotrexate in childhood rheumatic diseases Arthritis Rheum 41: 381-391.

33. Papadopoulou C, Kostik M, Böhm M, Nieto-Gonzalez JC, Gonzalez-Fernandez $\mathrm{Ml}$, et al. (2013) Methotrexate therapy may prevent the onset of uveitis in juvenile idiopathic arthritis. J Pediatr 163: 879-884

34. Foeldvari I, Wierk A (2005) Methotrexate is an effective treatment for chronic uveitis associated with juvenile idiopathic arthritis. J Rheumatol 32: 362-365.

35. Kalinina Ayuso V, van de Winkel EL, Rothova A, de Boer JH (2011) Relapse rate of uveitis post-methotrexate treatment in juvenile idiopathic arthritis. Am J Ophthalmol 151: 217-222.

36. Taylor SR, Banker A, Schlaen A, Couto C, Matthe E, et al. (2013) Intraocular methotrexate can induce extended remission in some patients in noninfectious uveitis. Retina 33: 2149-2154. 
Citation: Woo SJ, Kang EH (2013) Use of Methotrexate for the Treatment of Ocular Inflammation and Uveitis. JPharmacovigilance 1: 117. doi:10.4172/23296887.1000117

37. Taylor SR, Habot-Wilner Z, Pacheco P, Lightman S (2012) Intravitreal methotrexate in uveitis. Ophthalmology 119: 878-879.

38. Taylor SR, Habot-Wilner Z, Pacheco P, Lightman SL (2009) Intraocular methotrexate in the treatment of uveitis and uveitic cystoid macular edema. Ophthalmology 116: 797-801.

39. Lie E, van der Heijde D, Uhlig T, Heiberg MS, Koldingsnes W, et al. (2010) Effectiveness and retention rates of methotrexate in psoriatic arthritis in comparison with methotrexate-treated patients with rheumatoid arthritis. Ann Rheum Dis 69: 671-676.

40. Salliot C, van der Heijde D (2009) Long-term safety of methotrexate monotherapy in patients with rheumatoid arthritis: a systematic literature research. Ann Rheum Dis 68: 1100-1104.

41. Morgan SL, Baggott JE, Vaughn WH, Young PK, Austin JV, et al. (1990) The effect of folic acid supplementation on the toxicity of low-dose methotrexate in patients with rheumatoid arthritis. Arthritis Rheum 33: 9-18.

42. Morgan SL, Baggott JE, Vaughn WH, Austin JS, Veitch TA, et al. (1994) Supplementation with folic acid during methotrexate therapy for rheumatoid arthritis. A double-blind, placebo-controlled trial. Ann Intern Med 121: 833-841.
43. Joyce DA, Will RK, Hoffman DM, Laing B, Blackbourn SJ (1991) Exacerbation of rheumatoid arthritis in patients treated with methotrexate after administration of folinic acid. Ann Rheum Dis 50: 913-914.

44. Zhao R, Matherly LH, Goldman ID (2009) Membrane transporters and folate homeostasis: intestinal absorption and transport into systemic compartments and tissues. Expert Rev Mol Med 11: e4.

45. Barrera P, Laan RF, van Riel PL, Dekhuijzen PN, Boerbooms AM, et al. (1994) Methotrexate-related pulmonary complications in rheumatoid arthritis. Ann Rheum Dis 53: 434-439.

46. Imokawa S, Colby TV, Leslie KO, Helmers RA (2000) Methotrexate pneumonitis: review of the literature and histopathological findings in nine patients. Eur Respir J 15: 373-381.

47. Kremer JM, Alarcón GS, Weinblatt ME, Kaymakcian MV, Macaluso M, et al. (1997) Clinical, laboratory, radiographic, and histopathologic features of methotrexate-associated lung injury in patients with rheumatoid arthritis: a multicenter study with literature review. Arthritis Rheum 40: 1829-1837.

48. Alarcon GS, Kremer JM, Macaluso M, Weinblatt ME, Cannon GW, et al. (1997) Risk factors for methotrexate-induced lung injury in patients with rheumatoid arthritis. A multicenter, case-control study. Methotrexate-Lung Study Group. Ann Intern Med 127: 356-364. 